\title{
INTEGRATION OF PALSAR AND ASTER SATELLITE DATA FOR GEOLOGICAL MAPPING IN TROPICS
}

\author{
Amin Beiranvand Pour*, Mazlan Hashim \\ Geoscience and Digital Earth Centre (Geo-DEC) \\ Research Institute for Sustainability and Environment (RISE) \\ Universiti Teknologi Malaysia (UTM) \\ 81310 UTM Skudai, Johor Bahru, Malaysia \\ *Corresponding author: a.beiranvand@utm.my
}

\section{Commission VI, WG VI/4}

KEY WORDS: PALSAR; ASTER; Geological mapping; Gold exploration

\begin{abstract}
:
This research investigates the integration of the Phased Array type L-band Synthetic Aperture Radar (PALSAR) and the Advanced Spaceborne Thermal Emission and Reflection Radiometer (ASTER) satellite data for geological mapping applications in tropical environments. The eastern part of the central belt of peninsular Malaysia has been investigated to identify structural features and mineral mapping using PALSAR and ASTER data. Adaptive local sigma and directional filters were applied to PALSAR data for detecting geological structure elements in the study area. The vegetation, mineralogic and lithologic indices for ASTER bands were tested in tropical climate. Lineaments (fault and fractures) and curvilinear (anticline or syncline) were detected using PALSAR fused image of directional filters (N-S, NE-SW, and NW-SE).Vegetation index image map show vegetation cover by fusing ASTER VNIR bands. High concentration of clay minerals zone was detected using fused image map derived from ASTER SWIR bands. Fusion of ASTER TIR bands produced image map of the lithological units. Results indicate that data integration and data fusion from PALSAR and ASTER sources enhanced information extraction for geological mapping in tropical environments.
\end{abstract}

\section{INTRODUCTION}

Synthetic Aperture Radar (SAR) is an active microwave remote sensing system which can acquire data with high resolution regardless of day or night time, cloud, haze or smoke over a region. Clouds are reasonably transparent to microwave providing measurements with almost any weather conditions. Radar transmits and detects radiation between 2.0 to $100 \mathrm{~cm}$, typically at 2.5-3.8 cm (X-band), 4.0-7.5 cm (C-band), and 15.0-30.0 cm (L-band) (Campbell, 2007). Longer wavelengths optimize the depth of investigation of the radar signal. The long wavelengths allow radar to have complete atmospheric transmission. Generally, the approximate depth of penetration is equal to radar's nominal wavelength. L-band can observe the forest's underlying surface features as well as the canopy because of its penetration capability (Shimada and Isoguchi, 2002). Thus, in tropical environments having the persistent cloud coverage, dense to complete vegetation cover and limited bedrock exposures, L-band SAR data provide the possibility of obtaining more useable geological structure information from the ground (Pour and Hashim, 2014, 2015).

Phased Array type L-band Synthetic Aperture Radar (PALSAR) sensor is L-band synthetic aperture radar, with multi mode observation function (Fine mode, Direct downlink, ScanSar mode, and Polarimetric mode). It has multi polarization configuration ( $\mathrm{HH}, \mathrm{HV}, \mathrm{VH}$, and $\mathrm{VV}$ ), variable off-nadir angle (9.9 to 50.8 degrees), and switching spatial resolution (10 m, 30 $\mathrm{m}, 100 \mathrm{~m}$ for Fine, Polarimetric, and ScanSar modes, respectively) and swath width observation (30 km, $70 \mathrm{~km}$, and 250-350 km for Polarimetric, Fine and ScanSar modes, respectively) (Igarashi, 2001). High resolution (fine mode), Full polarimetry (multi-polarization mode), off nadir pointing function of PALSAR improved the accuracy of analyzing geological structure, distribution of rocks, and expected to be used for the first stage of ore deposits exploration (ERSDAC, 2006). Consequently, PALSAR data contain great contribution for the geological structural analysis in tropical regions.

The Advanced Spaceborne Thermal Emission and Reflection Radiometer (ASTER) is a multispectral imaging sensor that measure reflected and emitted electromagnetic radiation from Earth's surface and atmosphere in 14 bands. The spectral bands include: three visible and near infrared radiation (VNIR) bands ranging between 0.52 and $0.86 \mu \mathrm{m}$ with a spatial resolution of $15 \mathrm{~m}$; six shortwave infrared radiation (SWIR) bands from 1.6 to $2.43 \mu \mathrm{m}$ with a spatial resolution of $30 \mathrm{~m}$; and five recording thermal infrared radiation (TIR) bands in the 8.125-11.65 $\mu \mathrm{m}$ wavelength region with spatial resolution of $90 \mathrm{~m}$ (Pour and Hashim, 2011a, b, 2013).

Previous investigations demonstrated that the integration of microwave and optical remote sensing data provides more accurate information compared with individual sensor results (Pour et al., 2013, 2014). The response of radar is more a function of geometrical properties and the structure of the surface in comparison with surface reflection as in optical images (Abdikan et al., 2012). Thus, the integration of microwave remote sensing and optical images could play an important role in extracting lithological and structural information for geological mapping in tropical environments. 
Accordingly, the integration of PALSAR and ASTER data would produce comprehensive geological information for tropical environments by using suitable image processing algorithms. This research presents a remote sensing digital image approach for the PALSAR and ASTER data aimed at geological structure and mineral mapping in the Central Belt of the peninsular Malaysia (Figure 1), which has tropical climate.

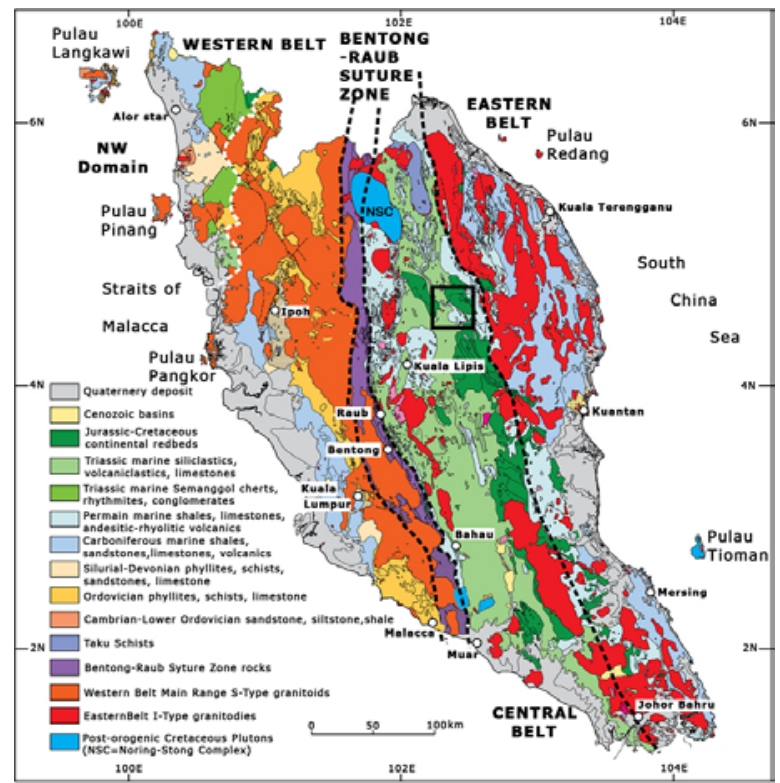

Figure 1. Simplified geological map of the peninsular Malaysia. Modified from Metcalfe, (2013). Study area is located in black cube.

\section{MATERIALS AND METHODS}

\subsection{Geology of the study area}

Peninsular Malaysia is divided into three geological belts based on stratigraphical and structural differences, namely the Eastern Belt, Central Belt, and Western Belt (Figure 1). The Central Belt contains thick Permian-Triassic marine carbonates, shales, volcaniclastics and andesitic volcanics, that are folded into broad kilometre scale open folds. The Central Belt is bounded by the Bentong-Raub Suture Zone to the west and the Lebir Fault Zone to the East (Metcalfe, 2013). This study focuses on the eastern part of the Central Belt (Figure 1). The study area was chosen based on remote sensing image availability of both PALSAR and ASTER data sets.

\subsection{Satellite remote sensing data}

A PALSAR and four ASTER scenes were obtained from the Earth and Remote Sensing Data Analysis Center (ERSDAC) Japan for the eastern part of Central Belt of peninsular Malaysia (http://gds.palsar.ersdac.jspacesystems.or.jp/e/). A PALSAR Fine Mode Dual polarization (FBD) Level 4.1 scene (PASL1000711251554201312148029) (Path/Row 487/8) used in this study was acquired on 25 November 2007. The ASTER data (ASTL1A0502190344360503140506) used in this study, consist of level 1B, 2B05S, 2B04 and 4A01Z products, were acquired on 19 February 2005. The datasets were processed using the ENVI (Environment for Visualizing Images) version 5.1 software package in this study.

\subsection{Image processing methods}

Radar images are inherently corrupted by speckle. Therefore, PALSAR data required to be filtered for speckle reduction. Accordingly, adaptive filtering was applied to the PALSAR data. Adaptive filters preserve image sharpness and detail while suppressing noise (Research Systems, Inc., 2008). The adaptive Local Sigma filter was selected for this study and applied to the Level 4.1 PALSAR image to accomplish speckle reduction and preserving both edges and features. The Local Sigma filter uses the local standard deviation computed for the filter box to determine valid pixels within the filter window. It replaces the pixel being filtered with the mean calculated using only the valid pixels within the filter box (Eliason and McEwen, 1990). In this study, Directional filters were applied to the PALSAR Local Sigma resultant image for edge enhancement and detailed identification of linear features. Edge enhancement delineates the edge and makes the shapes and details comprising the image more conspicuous. It can be used in geological applications to highlight faults and lineaments. Directional filter is a first derivative edge enhancement filter that selectively enhances image features having specific direction components (gradients) (Research Systems, Inc., 2008). Directional filters: N-S, E-W, NE-SW, and NW-SE with a $7 * 7$ kernel size were applied. $7 * 7$ kernel matrix was selected to enhance semi-smooth and smooth/rough features. Image Add Back value was entered $60 \%$. The Image Add Back value is the percentage of the original image that is included in the final output image.

Geometric and radiometric corrections have already been applied on the ASTER data products used in this study. The images were pre-georeferenced to UTM zone 40 North projection by using WGS-84 datum. Atmospheric correction was applied by Fast Line-of-sight Atmospheric Analysis of Spectral Hypercubes (FLAASH) algorithm (Thome et al., 1998). Because ASTER has 14 spectral bands, many permutations of ratio images, and thus more lithologic and mineralogic indices can be derived from ASTER data. Ninomiya (2005) defined a vegetation index and mineralogic indices for ASTER VNIR and SWIR bands, as well as and lithologic indices for ASTER TIR bands by considering the spectral absorption features of vegetation and different minerals and rocks in ASTER spectral channels. The resulting indices are listed as follows:

Stabilized Vegetation Index $(\mathrm{StVI})=\left[\frac{\text { band } 3}{\text { band } 2}\right]\left[\frac{\text { band } 1}{\text { band } 2}\right]$

OH bearing altered minerals Index $(\mathrm{OHI})=\left[\frac{\text { band } 7}{\text { band } 6}\right]\left[\frac{\text { band } 4}{\text { band } 6}\right]$

Kaolinite Index $(\mathrm{KLI})=\left[\frac{\text { band } 4}{\text { band } 5}\right]\left[\frac{\text { band } 8}{\text { band } 6}\right]$

Alunite Index (ALI) $=\left[\frac{\text { band } 7}{\text { band } 5}\right]\left[\frac{\text { band } 7}{\text { band } 8}\right]$

Calcite Index (CLI) $=\left[\frac{\text { band } 6}{\text { band } 8}\right]\left[\frac{\text { band } 9}{\text { band } 8}\right]$

Quartz Index $(\mathrm{QI})=\frac{(\text { band } 11 * \text { band } 11)}{\text { band } 10 * \text { band } 12}$

Carbonate Index $(\mathrm{CI})=\frac{\text { band13 }}{\text { band14 }}$ 
Mafic Index (MI) $=\frac{\text { band } 12}{\text { band } 13}$

These spectral indices have been applied to ASTER data covering eastern part of the Central Belt. These indices tested to detect vegetation, minerals, and lithological mapping in tropical environments. The resultant images are fused using Red-GreenBlue (RGB) color composites technique to produce image map of structural elements, clay minerals, and lithological units for the study area. The RGB color composites additive primary colors allow the assignment of three different types of information (e.g image channels) to the three primary RGB colors. The color composite facilitates the interpretation of multichannel image data due to the variations in colors based on the values in the single channels.

\section{RESULTS AND DISCUSSION}

Directional filters were applied to the PALSAR HH and HV polarization images. It seems that the $\mathrm{HV}$ polarization image is more suitable for lineament extraction and edge enhancement. Geological structures are more recognizable after directional filtering in the HV polarization image. Figure 2 shows fused image of N-S $\left(0^{\circ}\right)$, NE-SW $\left(45^{\circ}\right)$, and NW-SE $\left(135^{\circ}\right)$ directional filters applied on the HV polarization image. Lineaments and form-lines are detected. The western and northern parts of the image exhibit longer and more lineaments than eastern part. Two dominant directions can easily be identified, namely, NWSE and NE-SW sets of lineaments. The structural lines with NW-SE and NE-SW directions are in accordance with the tectonic framework of the study area. NW-SE striking is composed of continuous lineament in the central to western part of the image. However, in the eastern part of the image few lineaments are elongated to the NE-SW (Figure 2). Lineaments mapped in the image express several fold systems as curvilinear structures. Figure 2 shows an anticline with NW-SE trending in the central part and some curvilinear features in the south and eastern part of the image.

Stabilized vegetation index (StVI) has defined to indentify vegetation distribution on the ground using the VNIR bands of ASTER. It is produced by fusion of bands 1,2 and 3 of ASTER. According to this fusion, the most widely acknowledged vegetation index is Normalized Difference Vegetation Index (NDVI) defined as (NIR-red)/(NIR+red), where NIR and red correspond to ASTER band 3 and 2, respectively (Ninomiya, 2005). In this study, StVI was implemented to the VNIR bands of ASTER Level 1B product. Figure 3 shows the resultant image map of vegetation for the study area. Vegetation cover is identified as bright pixel (high DN value), which predominantly cover full scene (Figure 3 ). Clouds are appeared as black pixels in the center, north and south-western parts of the scene. However, water body, river and non-vegetated ground (anthropogenic activities region) are also manifested as dark pixels in the north-eastern, southeastern and north-western parts of the scene, respectively (Fig. $3)$.

The OHI, KLI and ALI indices have been applied to the ASTER level 1B and 2B05S products to identify the location of high concentration of clay minerals in the scene. Fusion of OHI, KLI and ALI indices as Red-Green-Blue (RGB) color combination were used to produce image map of clay minerals for the study area. Almost similar image map were derived from the ASTER level 1B and 2B05S products. Figure 4 shows the resultant image map derived from ASTER level 2B05S product.

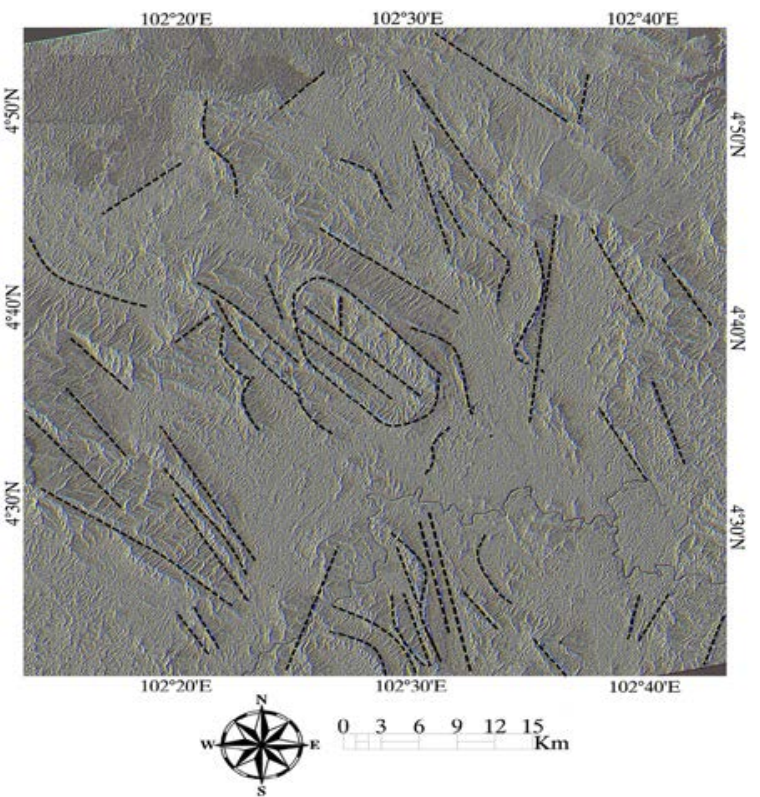

Figure 2. Fused image of N-S $\left(0^{\circ}\right)$, NE-SW $\left(45^{\circ}\right)$, and NW-SE $\left(135^{\circ}\right)$ directional filters applied on the HV polarization image for the study area.

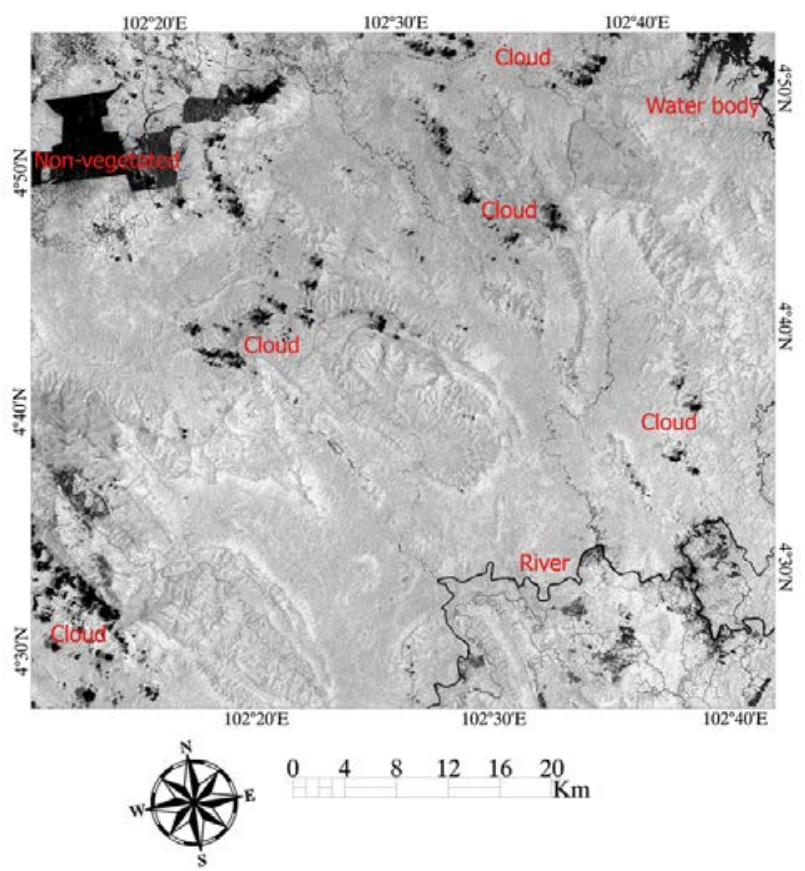

Figure 3. StVI resultant image map of vegetation for the study area.

High concentration of clay minerals is manifested as white and light yellow color in the image especially in the north-western part of the scene. Field reconnaissance, GPS survey and X-ray diffraction (XRD) analysis verified high concentration of clay minerals in the detected areas. 


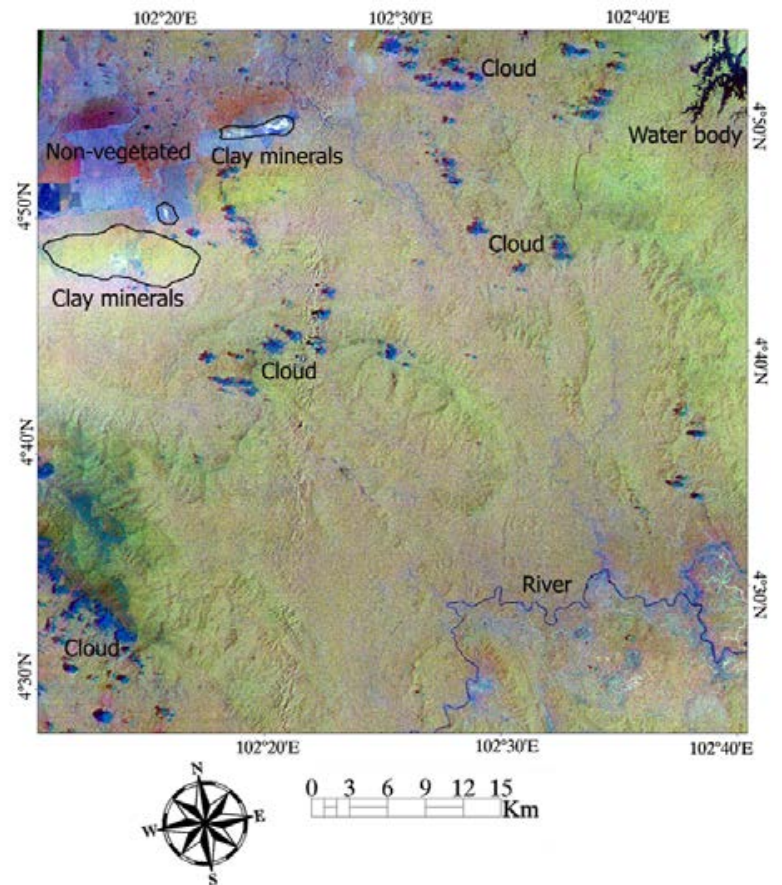

Figure 4. Fused image map of OHI, KLI and ALI indices as RGB color combination derived from ASTER level 2B05S product for the study area.

The ASTER TIR bands (10-14) are useful for detecting silicate and carbonate rocks (Ninomiya, 2005). These bands are located in the 8.125-11.65 $\mu \mathrm{m}$ wavelength region and measure emitted radiation from surface materials. Quartz is one of the important rock-forming minerals that does not have diagnostic spectral absorption feature in the visible and near infrared and shortwave infrared radiation regions, but display strong fundamental molecular absorption features in the thermal infrared region (8-12 $\mu \mathrm{m})$ (Hunt and Salisbury, 1976). Quartz shows absorption features in bands 10 and 12 of ASTER, and has high emissivity in band 14 . The common carbonate minerals such as calcite and dolomite have an absorption feature at band 14 and high emissivity at band 13 of ASTER (Rockwell and Hofstra, 2008).

The QI, CI and MI indices have been employed to the ASTER level 1B and 2B04 aim at the detection of quartz-rich and carbonate-rich rocks. Fusion of QI, CI and MI indices as RGB color combination were used to generate image map of the lithological units for the study area. Results extracted from level 2B04 product were not satisfactory in terms of lithological mapping. Figure 5 shows resultant image map derived from ASTER level 1B product. Quartz-rich rocks are depicted as brown and dark brown color, whereas quartz-low rocks are as light blue tone. Carbonate-rich rocks are appeared as grey hue (Figure 5).

Figure 6 shows Digital Elevation Model (DEM) generated from ASTER Level 4A01 product. Results show that most of the study area has elevation less than $1000 \mathrm{~m}$. South-western part of the image shows highest elevation (up to $2500 \mathrm{~m}$ ) region in the study area.

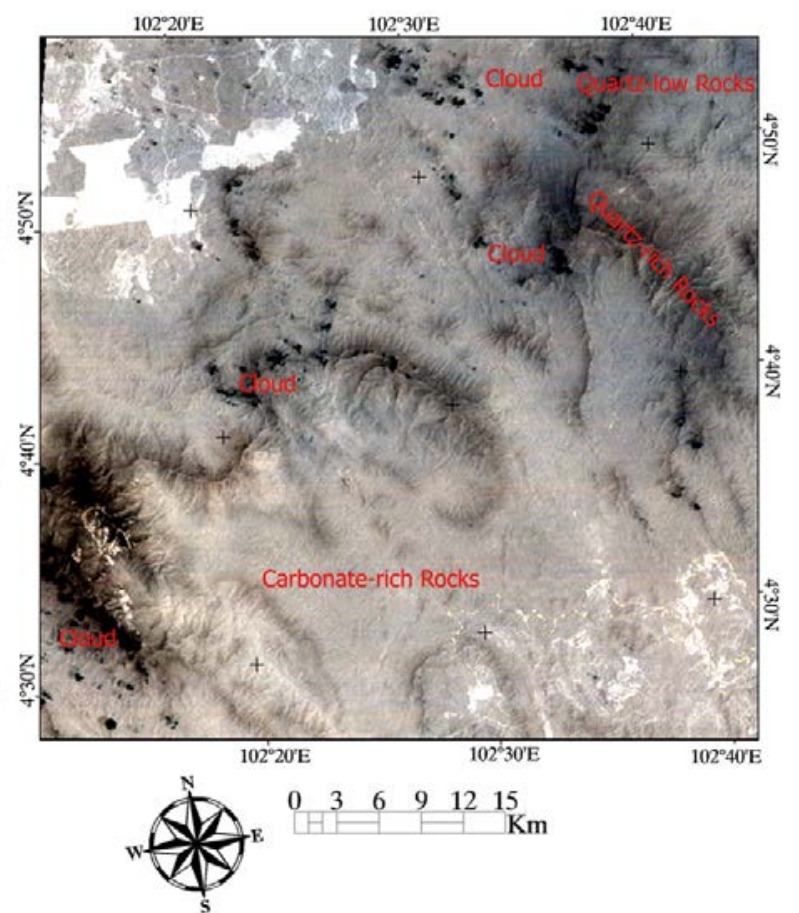

Figure 5. Fused image map of QI, CI and MI indices as RGB color combination derived from ASTER level 1B product for the study area.

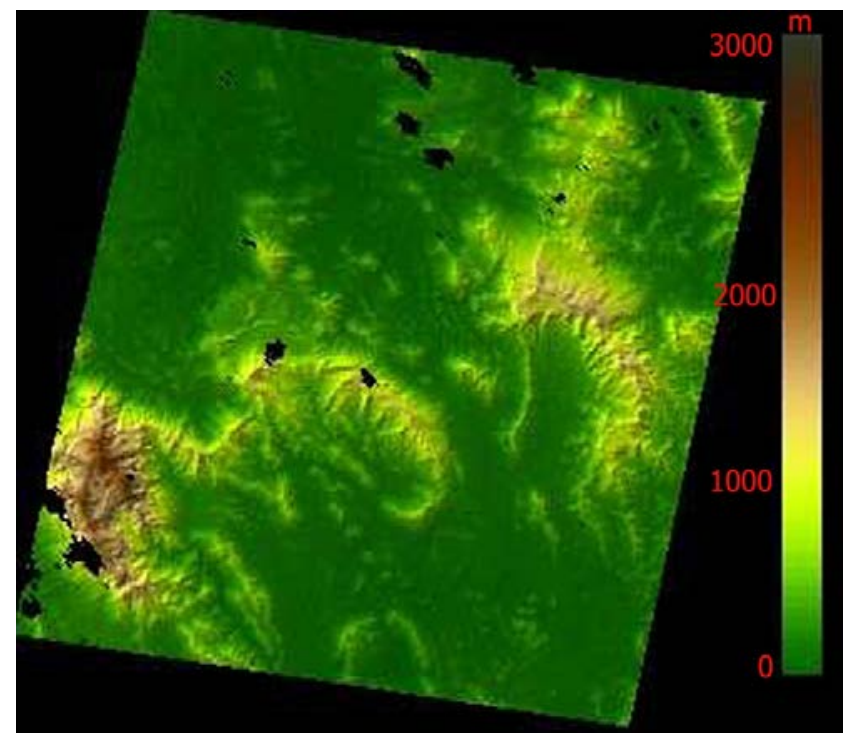

Figure 6. Digital Elevation Model (DEM) image map generated from ASTER Level 4A01 product for the study area.

\section{CONCLUSIONS}

In the present study, it is observed that the integrated images of PALSAR and ASTER data provide comprehensive geological information for tropical environments. Geological structures such as faults, fractures and anticline were detected using PALSAR fused image of directional filters (N-S, NE-SW, and NW-SE). StVI index image map showed vegetation cover by fusing ASTER VNIR bands. High concentration of clay minerals zone was detected using fused image map of OHI, KLI and ALI indices of the ASTER SWIR bands. Fusion of QI, CI and MI indices of ASTER TIR bands produced image map of 
the lithological units, including rich-quartz, low-quartz and high-carbonate rocks. This image integration technique could be utilized as an efficient tool for geological mapping and mineral exploration in tropical environments.

\section{ACKNOWLEDGEMENTS}

This study was conducted as a part of TRGS grant (Vote no: R.J130000.7809.4L837), Ministry of Higher Education (MOHE) Malaysia. We are thankful to the Universiti Teknologi Malaysia for providing the facilities for this investigation.

\section{REFERENCES}

Abdikan, S., F. B. Sanli, F. Sunar, and M. Ehlers., 2012. A comparative data-fusion analysis of multi-sensor satellite images. International Journal of Digital Earth. http://dx.doi.org/10.1080/17538947.2012.748846

Campbell, J.B., 2007. Introduction to remote sensing. The Guilford Press, New York.

Earth Remote Sensing Data Analysis Center (ERSDAC), 2006. PALSAR user's guide. $1^{\text {st }}$ Edition. March 2006.

Eliason, E.M. and McEwen, A.S., 1990. Adaptive Box Filters for Removal of Random Noise from Digital Images. Photogrammetric Engineering \& Remote Sensing, April, 1990, V56 No. 4, p. 453.

Igarashi, T., 2001. ALOS Mission requirement and sensor specifications. Advances in Space Research 28(1), 127-131.

Hunt, G. R. and Salisbury, J. W., 1976. Mid-infrared spectral behavior of metamorphic rocks, Technical Report AFRCL-TR76-0003, US Air Force Cambridge Research Laboratory, Cambridge, MA.

Metcalfe, I., 2013. Tectonic evolution of the Malay Peninsula. Journal of Asian Earth Sciences. 76, 195-213.

Ninomiya, Y., Fu, B. and Cudahy, T.J., 2005. Detecting lithology with Advanced Spaceborne Thermal Emission and Reflection Radiometer (ASTER) multispectral thermal infrared “radiance-at-sensor" data. Remote Sensing of Environment, 99 (1-2), 127-139.

Pour, B. A. and Hashim, M., 2011a. Application of Spaceborne Thermal Emission and Reflection Radiometer (ASTER) data in geological mapping. International Journal of the Physical Sciences, 6(33), 7657-7668.

Pour, A.B., Hashim, M., 2011b. Spectral transformation of ASTER data and the discrimination of hydrothermal alteration minerals in a semi-arid region, SE Iran. International Journal of the Physical Sciences 6, 2037-59.

Pour, B.A., Hashim, M., Van Genderen, J., 2013. Detection of hydrothermal alteration zones in a tropical region using satellite remote sensing data: Bau goldfield, Sarawak, Malaysia. Ore Geology Reviews, 54, 181-196.
Pour, A.B., Hashim, M. 2013. Fusing ASTER, ALI and Hyperion data for enhanced mineral mapping. International Journal of Image and Data Fusion, 4, 126-145.

Pour, A.B., Hashim, M., 2014. Structural geology mapping using PALSAR data in the Bau gold mining district, Sarawak, Malaysia, Adv. Space Research, vol.54 (4), pp. 644-654.

Pour, B. A., Hashim, M, Marghany. M., 2014. Exploration of gold mineralization in a tropical region using Earth Observing-1 (EO1) and JERS-1 SAR data: a case study from Bau gold field, Sarawak, Malaysia. Arabian Journal of Geosciences, 7, 23932406.

Pour, A.B., Hashim, M., 2015. Structural mapping using PALSAR data in the Central Gold Belt Peninsular Malaysia, Ore Geology Reviews, vol.64, pp. 13-22.

Research Systems, Inc., 2008. ENVI Tutorials. Research Systems, Inc., Boulder, CO.

Rockwell, B. W. and Hofstra, A.H., 2008. Identification of quartz and carbonate minerals across northern Nevada using ASTER thermal infrared emissivity data, implications for geologic mapping and mineral resource investigations in wellstudied and frontier areas. Geosphere, 4(1), 218-246.

Shimada, M., Isoguchi, O., 2002. JERS-1 SAR mosaics of South-EastAsia using calibrated path images. International Journal of Remote Sensing 23(7), 1507-1526.

Thome, K., Palluconi, F., Takashima, T. and Masuda, K., 1998. Atmospheric Correction of ASTER. IEEE Transactions of Geosciences and Remote Sensing, 36(4), 1119-1211. 